\title{
Welding-induced Residual Stresses in U-Ribs of a Steel Bridge Deck
}

\author{
Huili Wang ${ }^{1,2}$, Sifeng Qin ${ }^{3 *}$, Ben Wang ${ }^{4}$, Shaobo Zhou ${ }^{1}$ \\ ${ }^{1}$ National \& Local Joint Engineering Laboratory of Bridge and Tunnel Technology, Dalian University of Technology, Dalian, 116023, \\ China \\ ${ }^{2}$ State Key Laboratory of Structural Analysis for Industrial Equipment, Dalian University of Technology, Dalian, 116023, China \\ ${ }^{3}$ College of Civil Engineering and Architecture, Dalian University, Dalian 116022, China \\ ${ }^{4}$ Beijing General Municipal Engineering Design and Research Institute, Beijing 100082, China \\ * Corresponding author, e-mail: qinsifeng@dlu.edu.cn
}

Received: 26 February 2021, Accepted: 16 July 2021, Published online: 18 August 2021

\section{Abstract}

To calculate the welding-induced residual stresses in U-ribs of the steel deck plate and conduct quantitative analysis of influential factors, the U-ribs of steel deck plate of Xinghai Bay Bridge was taken as the research object. In the ABAQUS finite element software, the local models of U-ribs of steel deck plate were established. Nodal body force loads, i.e., heat generation rate, of the double ellipsoidal heat source models were applied via the compiled subsidiary Dflux program. The welding process of the v-groove welds was simulated, to obtain the residual stresses distribution in the top plate and U-rib plates. The influence of thickness of top plate and angle of welding groove on the residual stresses in the U-ribs were studied. The results show that the welding-induced residual stresses calculated by the numerical method proposed in this paper agree well with the experimental data. The maximum residual stresses in the top plates and the U-rib plates all occur near the welds, which exceeds the yielding limitation of the material. As the thickness of top plate increases, the maximum values of residual stresses in the top plates and U-ribs increase. However, with the increase of groove angle, the maximum values of residual stresses in the top plates and U-rib plates decrease.
\end{abstract}

\section{Keywords}

steel bridge deck, U-rib, double ellipsoidal heat source, residual stress, numerical simulation

\section{Introduction}

Orthotropic steel bridge deck has become the main form of deck system among steel bridges. Steel U-rib plates and top plates are connected by welding, which would cause residual stress [1]. The weld metal was stress-free while molting and can support residual stresses only after solidification. The very hot weld metal and heat-affected zone (HAZ) are cooled over a larger temperature range than the surrounding cooler material and therefore shrinks more. Thus, to maintain dimensional continuity through compatible longitudinal strains, large longitudinal tensile residual stresses are generated in the weld metal and HAZ balanced by compressive stresses in the surrounding material. The compressive residual stress will reduce the overall stability of the structure, while the tensile residual stress near the weld center will reduce the fatigue strength. Therefore, it is necessary to study the effect of welding-induced residual stresses on the U-rib of steel bridge deck [2].
The experiment is the most effective method to study welding-induced residual stresses. Boulton and Lance Martin [3] studied the mechanism of welding-induced residual stresses state. Gu et al. [4] proposed a prediction approach to estimate the welding distortion based on the local displacement in the weld plastic zone. In recent years, FEM had been widely used in evaluating the effects of welding temperature field, residual stress field and post-welding heat treatment. Ueda et al. [5] carried out a thermo-elastic-plastic finite element method to conduct transient analysis of stress and strain changes during welding. Goldak et al. [6,7] performed a double ellipsoidal welding heat source model, which considered the different distribution of heat source during the practical welding process. Attarha and Sattari-Far [8] predicted the temperature distribution of welding sheets by FEM. Perić et al. [9] conducted a thermo-mechanical 
finite element analysis with a shell/three-dimensional modeling technique. Zhu et al. [10] conducted the estimation of angular distortion and residual stresses of T-type fillet weld and butt weld specimens by applying the thermo-elastic-plastic, inherent strain and substructure methods. Kainuma et al. [11] measured the distribution of welding-induced residual stresses of steel bridge deck U-ribs at various weld penetrations with magnetostriction method. Wang et al. [12] investigated the welding-induced residual stresses of U-rib stiffened plates of the Ningbo Changhong bridge through numerical simulation and experimental methods. Zhao and $\mathrm{Wu}$ [13] and Zhao et al. [14] studied the distribution of residual stress on the top plate and U-rib plate of steel deck after welding and cooling by ANSYS numerical simulation and experiments. Kollár and Kövesdi [15] established the finite element model of corrugated web beam to simulate thermal cutting and welding, and analyzed the influence of manufacturing defects on the shear buckling behavior of corrugated web beam. Kollár and Kövesdi [16] introduced a systematic research program to evaluate the influence of manufacturing process on the shear buckling resistance, and to demonstrate the application possibilities of manufacturing simulation in the determination of resistance. Kollár et al. [17] introduced several numerical results of butt welded plates and box sections and focused on the determination of residual stresses and deformations due to different welding parameters. However, there were few studies on the variation trend of the welding-induced residual stresses of U-rib under the influence of variables such as different groove angles.
In this paper, welding-induced residual stresses in U-ribs of steel deck plate and influential factors were analyzed with ABAQUS. The welding process of the V-groove welds was modeled. Loads were applied to the double ellipsoidal heat source models via the compiled subsidiary Dflux program. The influence of thickness of top plate and angle of welding grooves on the residual stresses in the U-ribs were studied.

\section{Engineering background}

The U-rib of Xinghai Bay sea-crossing bridge is selected for analysis. The distance between the two main cables is $25.2 \mathrm{~m}$ (Fig. 1). The main span of Xinghai Bay sea-crossing bridge is $460 \mathrm{~m}$ in length, whereas the two end spans are $180 \mathrm{~m}$ (Fig. 2).

The bridge deck is made of orthotropic steel plate, with a width of $21.26 \mathrm{~m}$ (Fig. 3). Dimensions of the orthotropic steel plate are listed in Table 1.

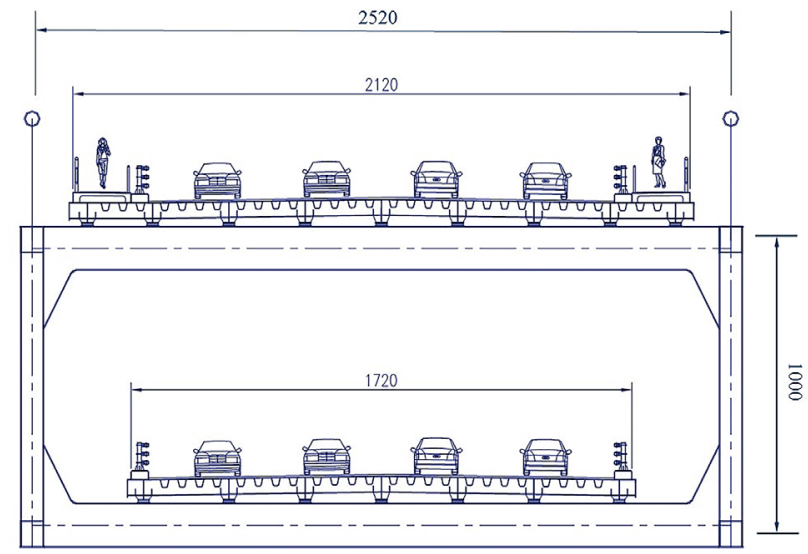

Fig. 1 Bridge cross section (cm)

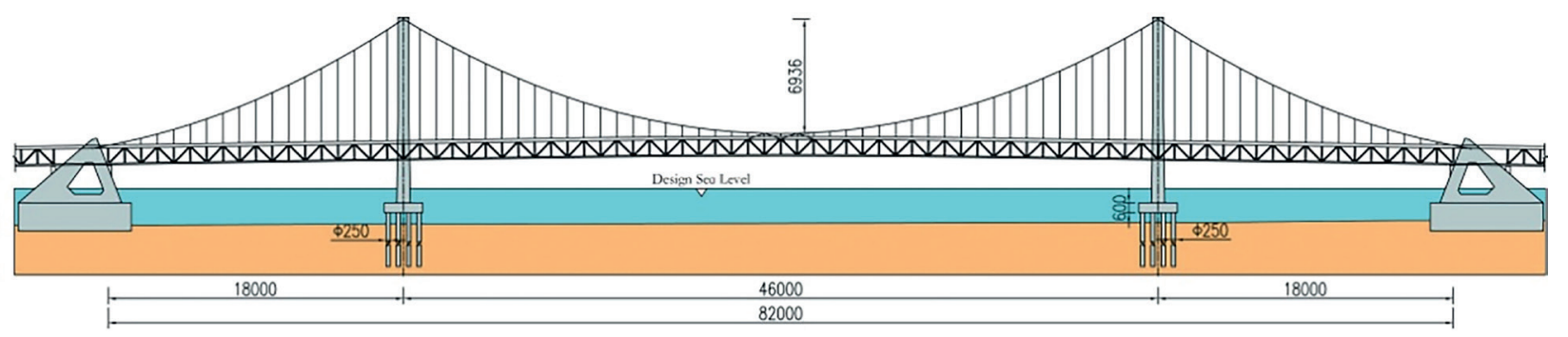

Fig. 2 Bridge elevation plan (cm)

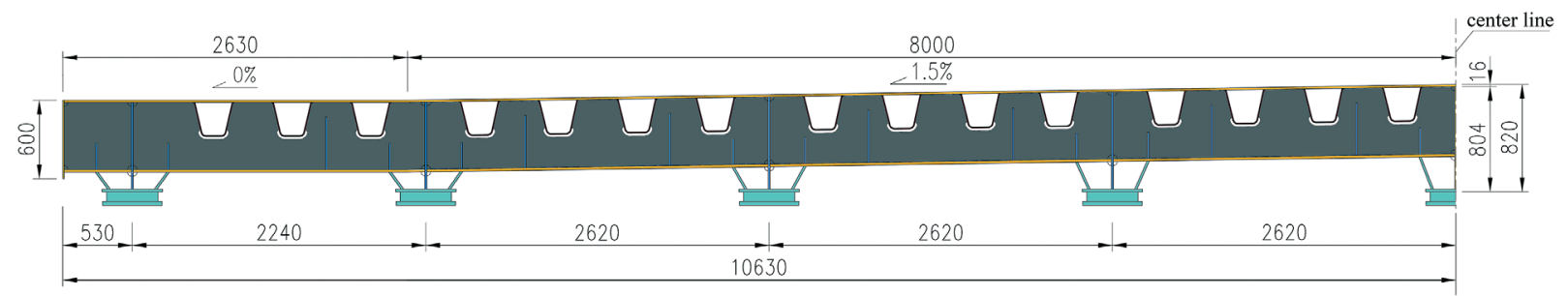

Fig. 3 Bridge deck cross section (mm) 
Table 1 The size of U-ribs

\begin{tabular}{lc}
\hline Items & Size $(\mathrm{mm})$ \\
thickness of top plate & 16 \\
thickness of of U-rib & 8 \\
width of U-rib & 300 \\
height of U-rib & 262 \\
height of fillet weld & 8 \\
\hline
\end{tabular}

The groove weld at U-rib end is $10 \mathrm{~mm}$ high with two layers. The cross-sectional geometry and welding details obtained by macro graphic measurement are shown in Fig. 4.

The deck is made of steel Q345. The nominal yield stress and ultimate tensile strength of the Q345 are 345 and $490 \mathrm{MPa}$ respectively. The latent heat of steel Q345 is $270000 \mathrm{~J} / \mathrm{kg}$, its solidus is $1460{ }^{\circ} \mathrm{C}$, and its liquidus is $1530^{\circ} \mathrm{C}$. The thermal properties curve of steel Q345 versus temperature are shown in Fig. 5 [18].

\section{Welding-induced temperature field}

The temperature field of the steel bridge deck U-rib is obtained by heat transfer analysis. The temperature field is taken as the temperature boundary condition. Then, the stress-strain field is obtained.

In order to reduce the amount of calculation, the U-rib finite element model is symmetrically simplified, as shown in Fig. 6. The 8-node solid heat transfer element is selected for temperature field simulation, which could transfer heat in surface and internal. In order to improve the computation accuracy, the elements near the weld of the model are refined.

\subsection{Simulation of welding-induced temperature field}

The heat source and filler metal $\left(1530^{\circ} \mathrm{C}\right)$ addition are simulated by combining methods of element birth and death technique with the double ellipsoidal heat source model. The heat power density distribution equation is divided into the front half part of the ellipsoid and the rear half part of the ellipsoid, as shown in Fig. 7 [19, 20].

Expression of ellipsoid heat source in the former half part is

$$
\begin{aligned}
& \text { FLUX }(1)=\text { heat }_{1} \times \text { shape }_{1}, \\
& \text { heat }_{1}=\frac{6 \sqrt{3} q f_{1}}{a b c_{1} \pi \sqrt{\pi}}, \\
& \text { shape }_{1}=e^{-3\left(\frac{\left(x-x_{0}\right)^{2}}{a^{2}}+\frac{\left(y-y_{0}-d\right)^{2}}{c_{1}^{2}}+\frac{\left(z-z_{0}\right)^{2}}{b^{2}}\right) .}
\end{aligned}
$$

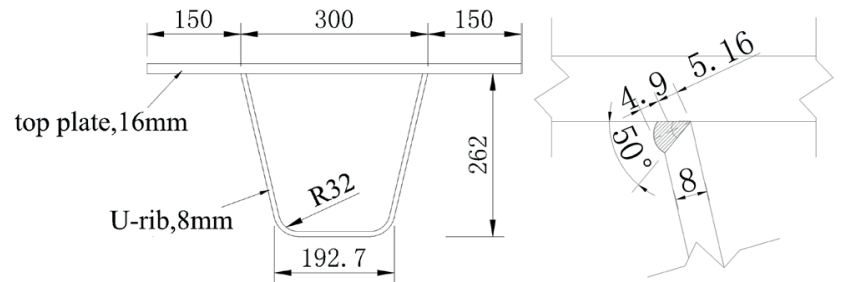

Fig. 4 Cross section of U-rib (mm)

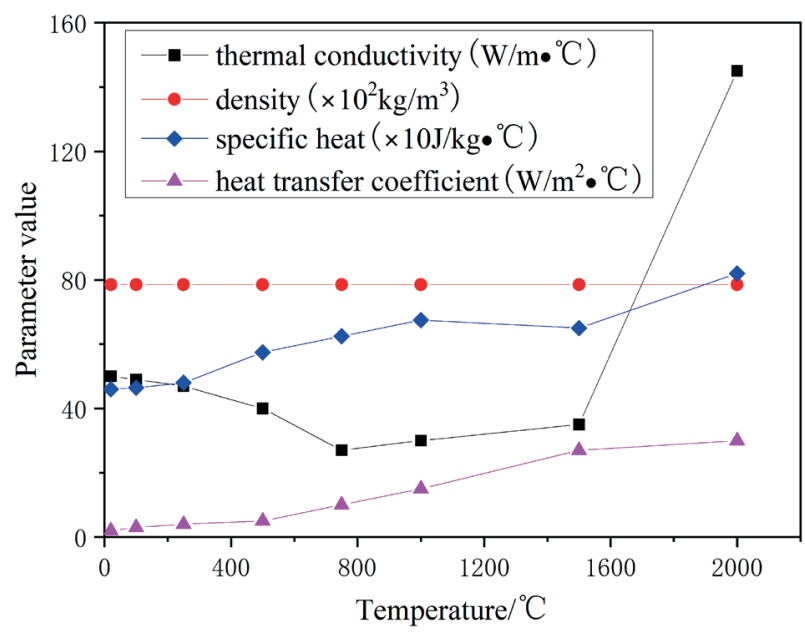

Fig. 5 Thermal properties of steel Q345 VS temperature

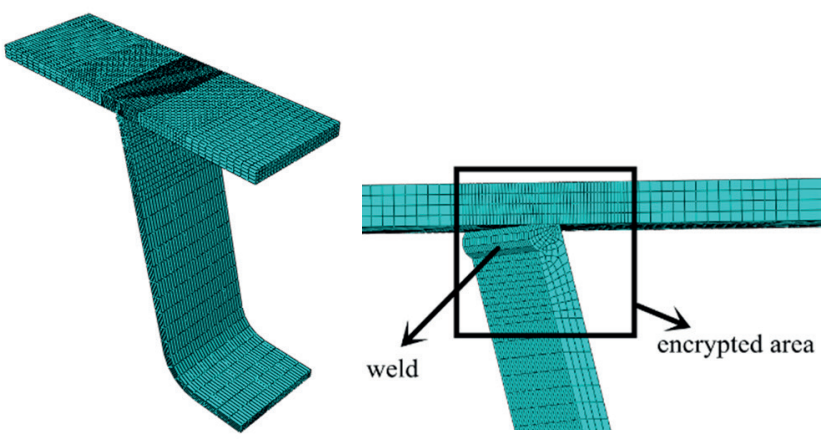

Fig. 6 Finite element model of U-rib

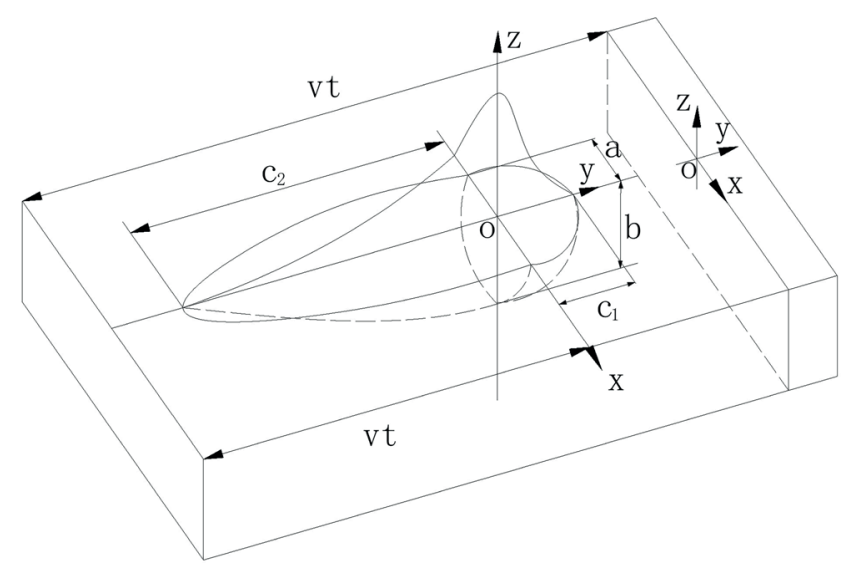

Fig. 7 Double ellipsoidal heat source model 
Expression of ellipsoid heat source in the rear half part is

$\operatorname{FLUX}(2)=$ heat $_{2} \times$ shape $_{2}$,

heat $_{2}=\frac{6 \sqrt{3} q f_{2}}{a b c_{2} \pi \sqrt{\pi}}$,

shape $_{2}=e^{-3\left(\frac{\left(x-x_{0}\right)^{2}}{a^{2}}+\frac{\left(y-y_{0}-d\right)^{2}}{c_{2}^{2}}+\frac{\left(z-z_{0}\right)^{2}}{b^{2}}\right)}$.

Where $F L U X(1), F L U X(2)$ indicates the heat flux density of the former and rear ellipsoids. $q$ is total power.

$q=\eta U I$

Where $\eta$ is welding efficiency. $U$ is welding voltage. $I$ is welding current. $f_{1}$ and $f_{2}$ are the proportions of heat energy distribution in the former and rear ellipsoids, and $f_{1}+f_{2}=1 . a$ is half width of heat source. $b$ is the depth of heat source. $c_{1}$ is the length of the first half of the ellipsoid. $c_{2}$ is the length of the rear half of the ellipsoid. $x_{0}, y_{0}, z_{0}$ is the starting point for the welding. $\mathrm{d}$ is the moving distance for heat source. The heat source parameters used in Eqs. (1) to (6) are summarized in Table 2.

At present, there is no direct method to simulate the mobile heat source. The Dflux subroutine is compiled with Fortran language, which can simulate the welding voltage, current, thermal efficiency, welding speed, welding starting point coordinates, and double-ellipsoid heat source, etc. The Dflux subroutine is associated with ABAQUS, and then the welding heat source of the U-rib of the steel bridge panel is loaded. According to the coordinates of each point, its position on the ellipsoidal heat source is determined. Then the heat flux of each point is given.

The weld between the top plate of the Xinghai Bay sea-crossing Bridge and the U-ribs of the bridge deck is a $\mathrm{v}$-shaped groove weld with two layers. The first layer is the bottom welding and the second layer is the filler welding. The welding variables are listed in Table 3 . The welding of the second layer of welds is started after the first layer of welds is cooled to below $200^{\circ} \mathrm{C}$.

Table 2 Parameters of the heat source

\begin{tabular}{lcc}
\hline Parameter & value & Remark \\
\hline$a$ & $3.5 \mathrm{~mm}$ & \\
$b$ & $5.0 \mathrm{~mm}$ & \\
$c_{1}$ & $5.0 \mathrm{~mm}$ & \\
$c_{2}$ & $10.0 \mathrm{~mm}$ & $f_{1}=2 c_{2} /\left(c_{1}+c_{2}\right)$ \\
$f_{1}$ & 1.33 & $f_{2}=2 c_{1} /\left(c_{1}+c_{2}\right)$ \\
$f_{2}$ & 0.67 & \\
\hline
\end{tabular}

Table 3 The welding variables

\begin{tabular}{lc}
\hline Parameter & Value \\
\hline speed & $8 \mathrm{~mm} / \mathrm{s}$ \\
voltage & $24 \mathrm{~V}$ \\
current & $220 \mathrm{~A}$ \\
thermal efficiency & 0.75 \\
\hline
\end{tabular}

\subsection{Results of temperature field}

The length of weld is $10 \mathrm{~cm}$. The welding between top plate and U-rib consists of two layers. When the first layer is welded, the second layer elements are in passivated state. The cooling time between the two layers is $25 \mathrm{~s}$, so that there is a certain preheating temperature during the second welding, and the residual stress field is smoother. After the second layer is welded, it is finally cooled to environment temperature of $36000 \mathrm{~s}$. The temperature distribution curves of the first layer at $2 \mathrm{~s}, 6 \mathrm{~s}$, and $10 \mathrm{~s}$ are shown in Fig. 8. The temperature distribution curves of the second layer at $40 \mathrm{~s}, 44 \mathrm{~s}$, and $48 \mathrm{~s}$ are shown in Fig. 9.

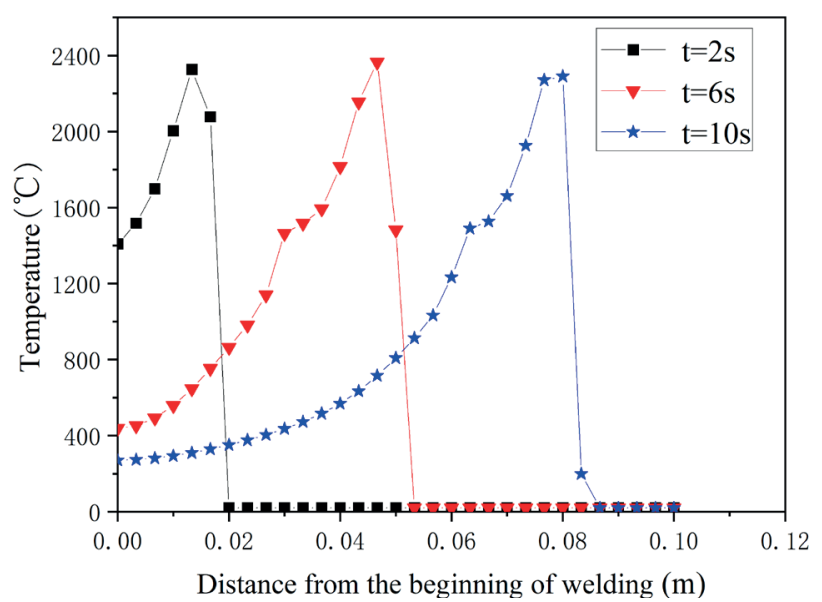

Fig. 8 Temperature distribution curves of the first layer

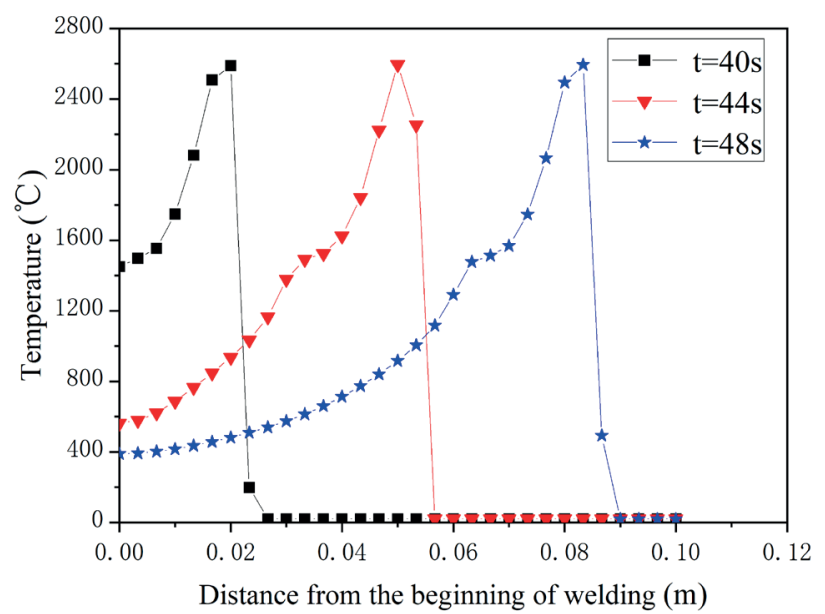

Fig. 9 Temperature distribution curves of the second layer 
It can be seen from Fig. 8 and Fig. 9 that the temperature distribution curves of the weld centerline have the same trend. The maximum temperature appears near the center of the heat source. The peak temperature of the first layer is $2300{ }^{\circ} \mathrm{C}$, and that of the second layer is $2500{ }^{\circ} \mathrm{C}$. Both first layer temperature field and second layer temperature field are quasi steady. The higher the welding temperature the closer to the center of heat source, which is consistent with the theoretical analysis results.

\section{Welding-induced residual stresses}

\subsection{Residual stress field simulation}

Some material parameters of Q345 vary with temperature. The curve of material parameter V.S. temperature is shown in Fig. 10 [18]. In order to ensure the accuracy of the calculation, the 3-D solid 8-node reduced-integration element is selected for the analysis.

The symmetrical constraints are applied on top plate and U-rib. The residual stress is caused by the non-uniform distribution of temperature field. The previously obtained temperature field should be introduced as external nodal loads acting on the finite element model. The initial temperature condition is $20^{\circ} \mathrm{C}$.

\subsection{Results of residual stress field}

In order to analyze the distribution of the residual stress field of the top plate, three paths are set on the top plate. The Path1 is near the bottom of the weld, the Path2 is the centerline of the top plate, and the Path3 is the top surface of the top plate, as shown in Fig. 11.

The residual stress of the top plate is shown in Fig. 12 .

As shown in Fig. 12, there is a peak region in the range of 3.75 times the thickness of U-rib, while there is a partial compressive residual stress in the area far away from the weld. There is no compressive residual stress on Path1, and its maximum tensile residual stress reaches to $449 \mathrm{MPa}$, which is approximately 1.3 times the yield strength of Q345. On Path2 the compressive residual stress region is within $0.02 \mathrm{~m}$ from the weld. The maximum tensile residual stress of Path2 is $75 \mathrm{MPa}$, while the maximum compressive residual stress of Path3 is about $200 \mathrm{MPa}$.

In order to analyze the residual stress field of double ellipsoidal heat source models, three paths are defined. The Path4 is the inner line of U-rib, the Path5 is the center line of U-rib, and the Path6 is the outer line of U-rib, as shown in Fig. 13. The starting point of the paths starts from the edge of the weld bead.

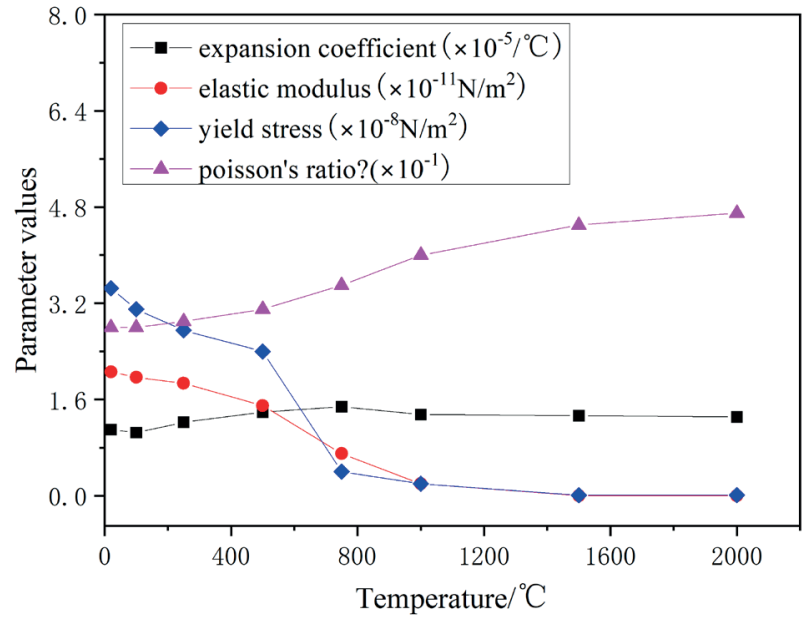

Fig. 10 Temperature variation curve of mechanical properties in steel Q345

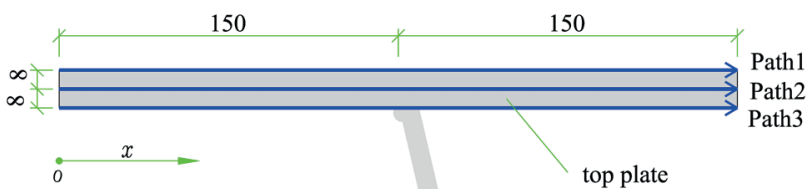

U-rib

Fig. 11 Three paths for the analysis of the top plate $/ \mathrm{mm}$

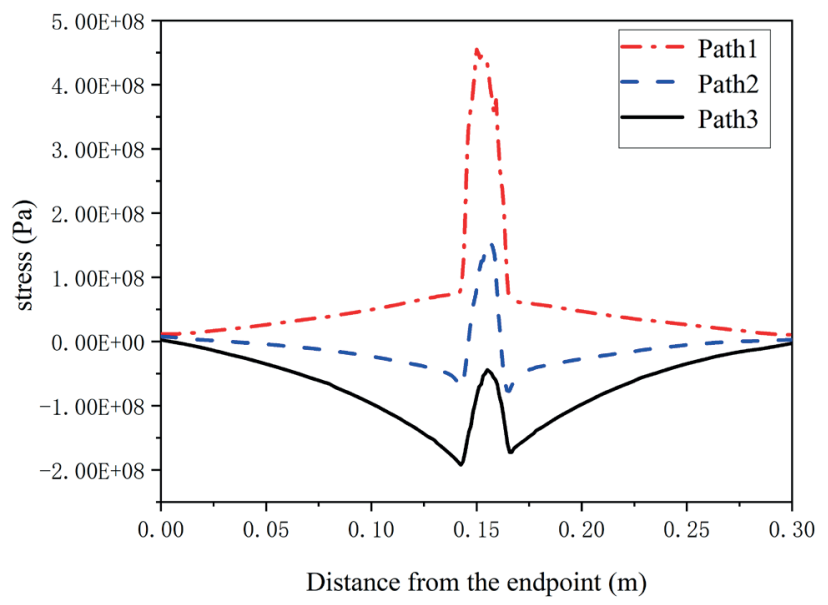

Fig. 12 Residual stress field along the paths

The residual stress field along the paths are shown in Fig. 14.

The residual stress of each path of U-ribs is almost the same, so the residual stress of U-ribs is uniform along the plate thickness direction. There is maximum tensile residual stress near the weld, reaching to $392 \mathrm{MPa}$, which exceeds the yield limit of the material. The maximum compressive residual stress of Path4 is $25 \mathrm{MPa}$, that of Path5 is $30 \mathrm{MPa}$, and that of Path6 is $75 \mathrm{MPa}$. 


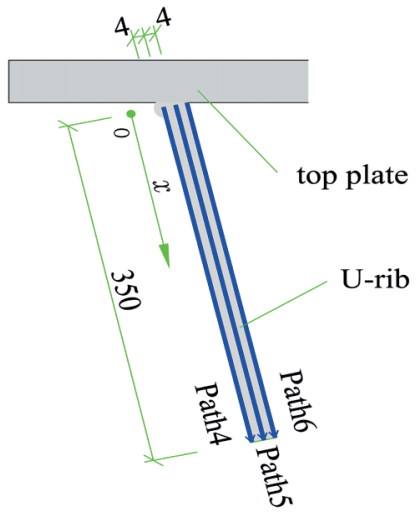

Fig. 13 Three paths of the U-rib / mm

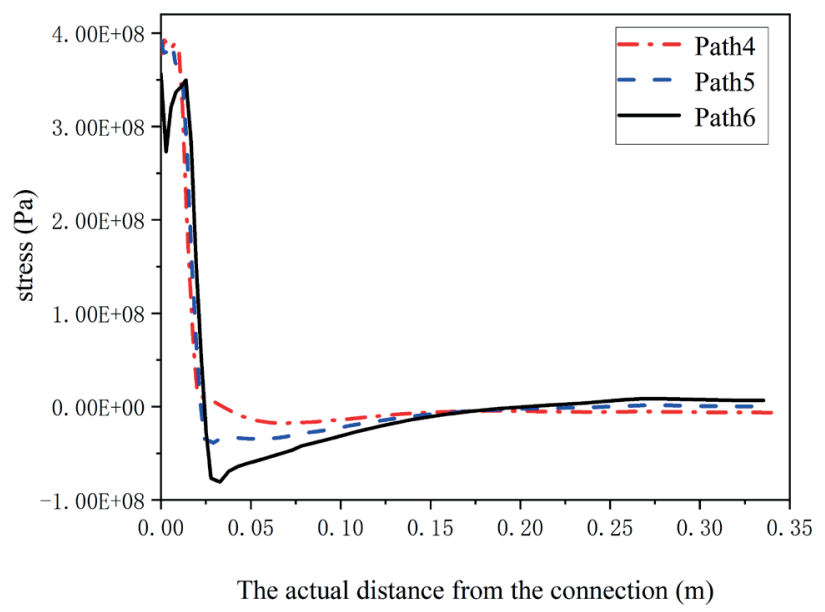

Fig. 14 Residual stress field along the paths

\section{Discussions}

\subsection{Comparative analysis with the experiment}

Zhao and $\mathrm{Wu}$ [13] used the strip cutting method to test the residual stress of the top plate and the U-ribs. In the direction where the residual stress needs to be measured, he cut the components into a large number of narrow strips and obtained the stress from the released strain. The cross-sectional dimension of the specimens is shown in Fig. 15.

The FEM residual stress results of the top plate and U-rib are compared with the test data as shown in Figs. 16 and 17.

The stress ratio is, where is the yield strength of the material. The FEM results agree well with the experimental data, which shows that the numerical simulation method in this paper is correct, reliable and suitable for engineering application.

\subsection{Parameter analysis}

There are numerous factors affecting the welding-induced residual stresses, including the properties of the material, the design of the structure, and the manufacturing process

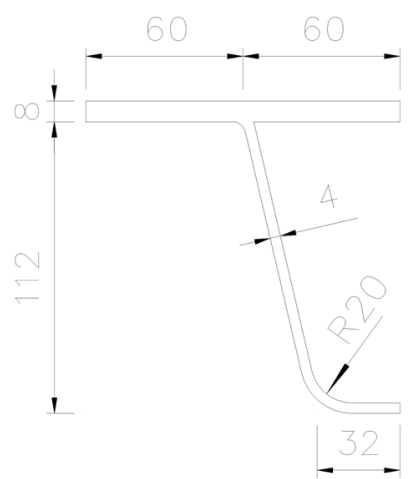

Fig. 15 Section sizes of specimen $(\mathrm{mm})$

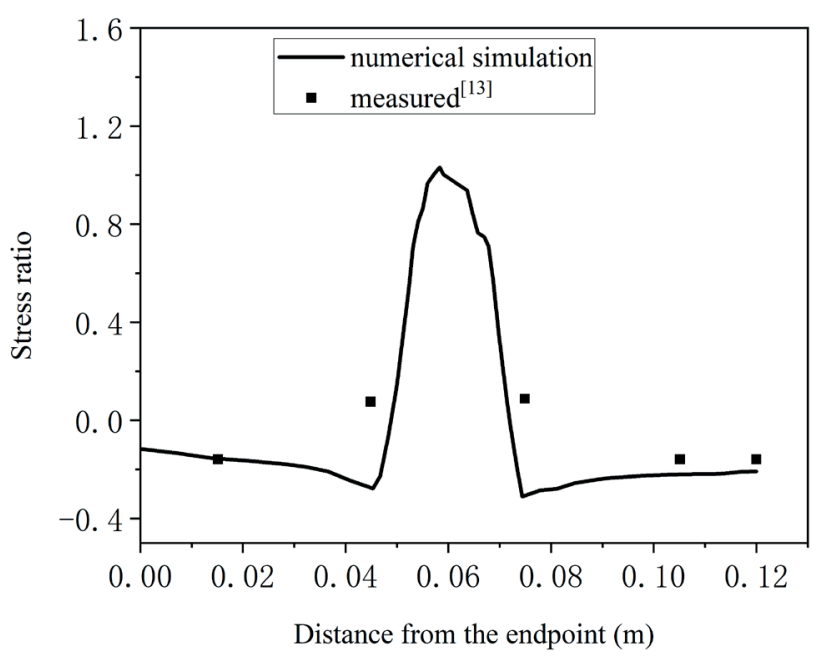

Fig. 16 residual stress of top plate

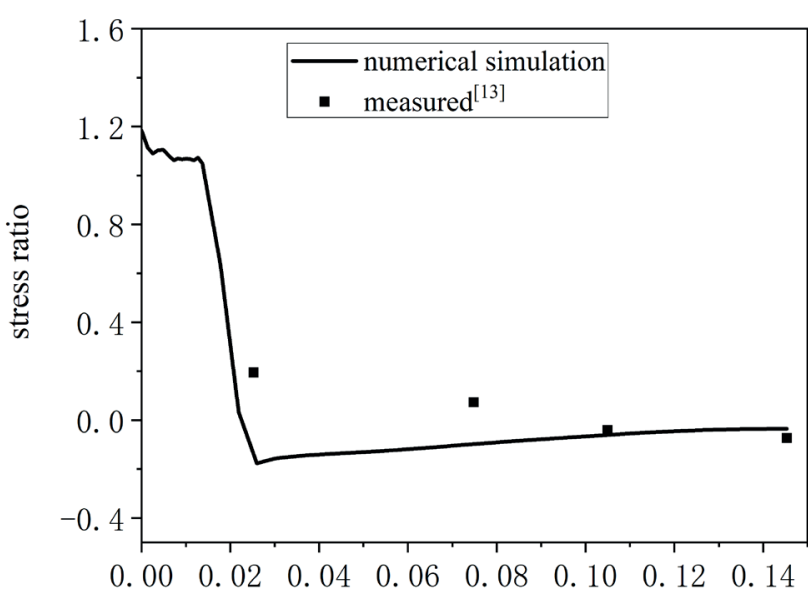

Distance from the welding center (m)

Fig. 17 residual stress of U-rib

and other parameters. It is essential to study the influence of the structural parameters on the welding-induced residual stresses. The thickness of the top plate and the welding angle have a great influence on the residual stress of the U-ribs. 


\subsubsection{Effect of plate thickness on residual stress}

The effect of plate thickness on the residual stress is studied. The plate thicknesses of the top plate ranged from 12 $\mathrm{mm}$ to $18 \mathrm{~mm}$ with an interval of $2 \mathrm{~mm}$. The curve of relative residual stresses is shown in Fig. 18.

It can be seen that with the increases of thickness of the plate, the maximum value of tensile residual stress of the plate increases. In the region far from the weld zone, the tensile residual stress is less affected by the thickness of the plate.

\subsubsection{Effect of the bevel angle on the residual stress}

The bevel angle of the weld has influence on the residual stress, so it is necessary to select a proper bevel angle. The effect of bevel angle on the residual stress is studied. The bevel angle ranged from $40^{\circ}$ to $55^{\circ}$ with an interval of $5^{\circ}$. The curve of relative residual stresses is shown in Fig. 19.

It can be seen that with the increases of bevel angle, the maximum value of tensile residual stress of the plate decreases. In the region far from the weld zone, the tensile residual stress is less affected by bevel angle.

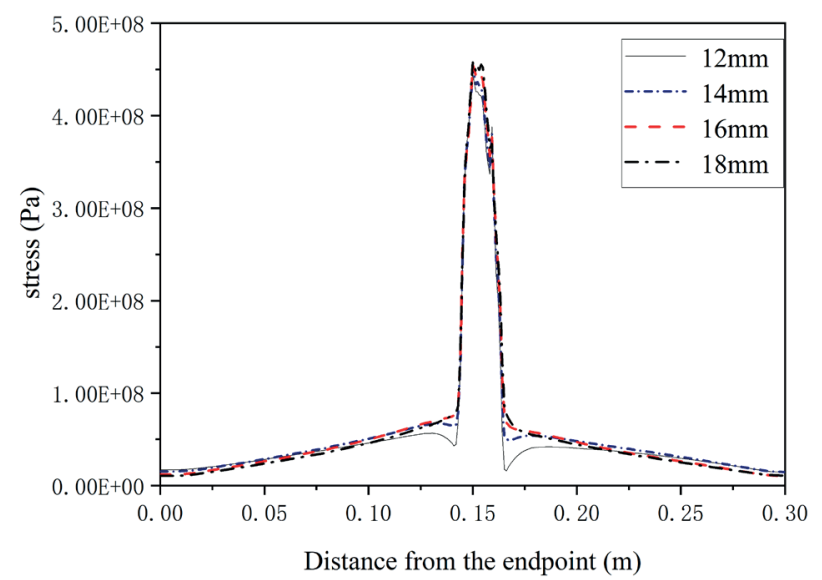

(a)

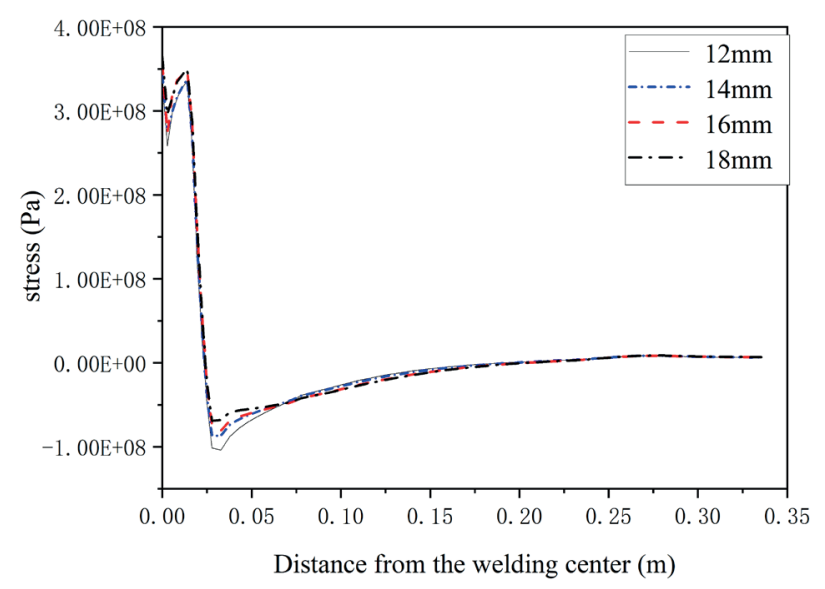

(b)

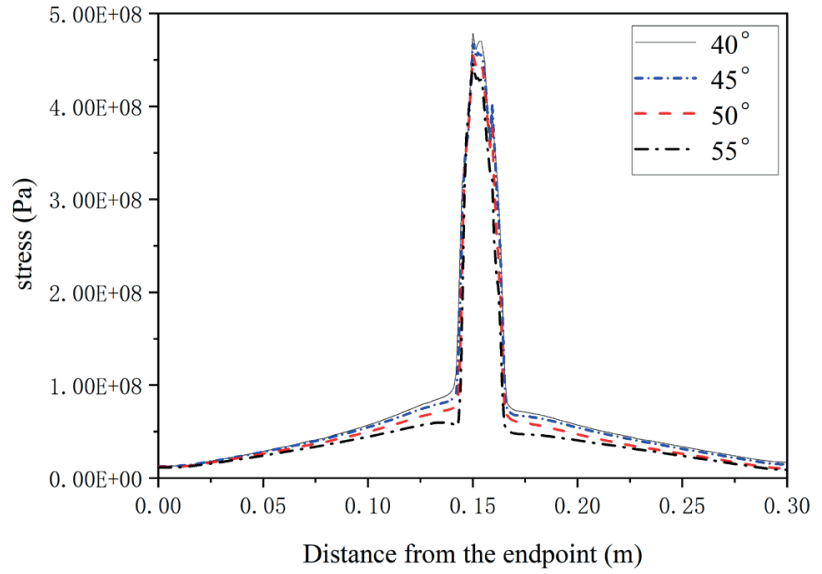

(a)

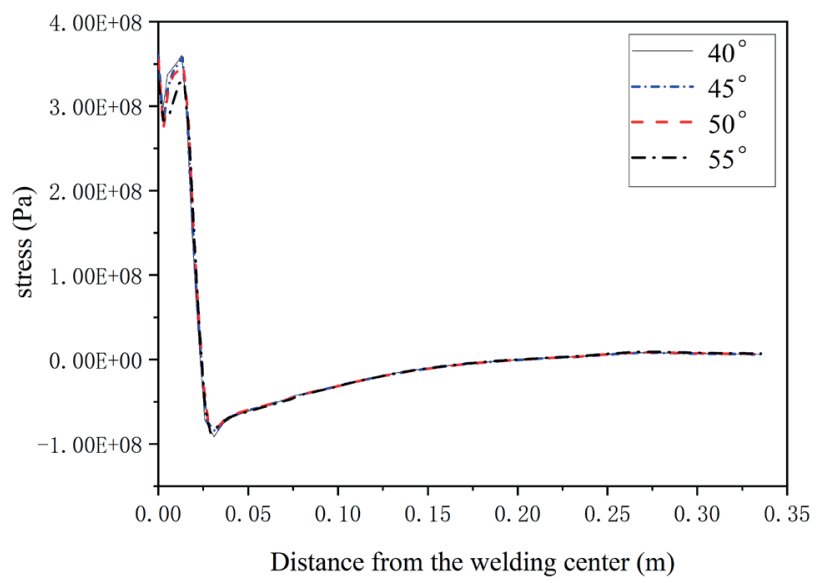

(b)

Fig. 19 residual stress curve (a) top plate, (b) U-rib

\section{Conclusions}

(1) The value of the residual stress in the direction of the weld exceeds the yield limit of the material. There is a peak region in the range of 3.75 times the thickness of U-rib, and the maximum tensile residual stress is near the weld.

(2) The residual stress of the top plate and U-rib are distributed uniformly along the plate thickness, and the maximum tensile residual stress appears near the weld.

(3) With the increase of the thickness of the top plate, the peak residual stress of top plate and U-ribs increase.

(4) With the increase of bevel angle, the tensile residual stress values of the top plate and the U-rib plate decrease.

\section{Acknowledgement}

This work is supported by the Liaoning Provincial Doctoral Scientific Foundation Projects (20170520138) and the Liaoning Provincial Natural Science Foundation Guidance Projects (2019-ZD-0006)

Fig. 18 residual stress curve (a) top plate, (b) U-rib 


\section{References}

[1] Deng, D., Murakawa, H. "Prediction of welding distortion and residual stress in a thin plate butt-welded joint", Computational Materials Science, 43(2), pp. 353-365, 2008.

https://doi.org/10.1016/j.commatsci.2007.12.006

[2] Dihd, R. "Welding residual stress and distortion", In: Heat Effects of Welding, Springer, Berlin Heidelberg, Germany, 1992, pp. 129-246. http://doi.org/10.1007/978-3-642-48640-1_3

[3] Boulton, N. S., Lance Martin, H. E. "Residual Stresses in Arc-Welded Plates", Proceedings of the Institution of Mechanical Engineers, 133(1), pp. 295-347, 1936.

https://doi.org/10.1243/PIME_PROC_1936_133_017_02

[4] Gu, Y., Li, Y. D., Qiang, B., Boko-haya, D. D. "Welding distortion prediction based on local displacement in the weld plastic zone", Welding in the World, 61(2), pp. 333-340, 2017.

https://doi.org/10.1007/s40194-016-0418-5

[5] Ueda, Y., Fukuda, K., Nakacho, K., Endo, S. "A New Measuring Method of Residual Stresses with the Aid of Finite Element Method and Reliability of Estimated Values", Journal of the Society of Naval Architects of Japan, 1975(138), pp. 499-507, 1975. https://doi.org/10.2534/jjasnaoe1968.1975.138_499

[6] Goldak, J., Chakravarti, A., Bibby, M. "A new finite element model for welding heat sources", Metallurgical Transactions B, 15(2), pp. 299-305, 1984.

https://doi.org/10.1007/BF02667333

[7] Goldak, J., Bibby, M., Moore, J. "Computer modeling of heat flow in welds", Metallurgical Transactions B, 17(3), pp. 587-600, 1986. https://doi.org/10.1007/BF02670226

[8] Attarha, M. J., Sattari-Far, I. "Study on welding distribution in thin welded plates through experimental measurements and finite element simulation", Journal of Materials Processing Technology, 211(4), pp. 688-694, 2011.

https://doi.org/10.1016/j.jmatprotec.2010.12.003

[9] Perić, M., Tonković, Z., Karšaj, I., Dragi, S. "A simplified engineering method for a T-joint welding simulation", Thermal Science, 22(3), pp. 867-873, 2018. https://doi.org/10.2298/TSCI171108020P

[10] Zhu, J., Khurshid, M., Barsoum, Z. "Accuracy of computational welding mechanics methods for estimation of angular distortion and residual stresses", Welding in the World, 63(5), pp. 1391-1405, 2019.

https://doi.org/10.1007/s40194-019-00746-9
[11] Kainuma, S., Yang, M., Jeong, Y.-S., Inokuchi, S., Kawatab, A., Uchida, D. "Experiment on fatigue behavior of rib-to-deck weld root in orthotropic steel decks", Journal of Constructional Steel Research, 119, pp. 113-122, 2016.

https://doi.org/10.1016/j.jcsr.2015.11.014

[12] Wang, F., Lyu, Z., Zhao, Z., Chen, Q., Mei, H. "Experimental and numerical study on welding residual stress of U-rib stiffened plates", Journal of Constructional Steel Research, 175, Article number: 106362, 2020.

https://doi.org/10.1016/j.jcsr.2020.106362

[13] Zhao, Q., Wu, C. "Numerical analysis of welding residual stress of U-rib stiffened plate", Engineering Mechanics, 29(8), pp. 262-268, 2012.

https://doi.org/10.6052/j.issn.1000-4750.2010.12.0935

[14] Zhao, Q., Guo, Z., Shen, X. "Test study on residual stress distribution of hybrid steel u-rib stiffened plates", Journal of Constructional Steel Research, 121, pp. 261-267, 2016. https://doi.org/10.1016/j.jcsr.2016.01.024

[15] Kollár, D., Kövesdi, B. "Welding simulation of corrugated web girders - Part 1: Effect of manufacturing on residual stresses and imperfections", Thin-Walled Structures, 146, Article number: 106107, 2020. https://doi.org/10.1016/j.tws.2019.04.006

[16] Kollár, D., Kövesdi, B. "Welding simulation of corrugated web girders - Part 2: Effect of manufacturing on shear buckling resistance", Thin-Walled Structures, 141, pp. 477-488, 2019. https://doi.org/10.1016/j.tws.2019.04.035

[17] Kollár, D., Kövesdi, B., Néző, J. "Numerical Simulation of Welding Process - Application in Buckling Analysis", Periodica Polytechnica Civil Engineering, 61(1), pp. 98-109, 2017. https://doi.org/10.3311/PPci.9257

[18] Lijun, Q., Huanqun, L., Yueqin, W. "Material properties of Q345 (16Mn) steel under loading and constant temperature", China Civil Engineering Journal, 7, pp. 33-40, 2008. https://doi.org/10.3321/j.issn:1000-131X.2008.07.006

[19] Deng, D. "FEM prediction of welding residual stress and distortion in carbon steel considering phase transformation effects", Materials \& Design, 30(2), pp. 359-366, 2009. https://doi.org/10.1016/j.matdes.2008.04.052

[20] Guangfei, G., Yong, W., Tao, H. "Application of Double Ellipsoid Heat Source Parameters Adjustment in Predicting the Size of In-Service Welding Pool", Pressure Vessel Technology, 30(1), pp. 15-19, 2013. https://doi.org/10.3969/j.issn.1001-4837.2013.01.002 